\title{
Determination of Phenolic Acids and Quercetin in Brazilian Red Wines from Vale do São Francisco Region Using Liquid-Liquid Ultrasound-Assisted Extraction and HPLC-DAD-MS
}

\author{
Fabio de S. Dias, ${ }^{*, a}$ Jorge M. David ${ }^{*, b}$ and Juceni P. David ${ }^{b}$ \\ ${ }^{a}$ Centro de Ciências Exatas e Tecnológicas, Universidade Federal do Recôncavo da Bahia, \\ 44380-000 Cruz das Almas-BA, Brazil \\ ${ }^{b}$ Instituto de Química, Universidade Federal da Bahia, Campus Ondina, 40170-290 Salvador-BA, Brazil
}

\begin{abstract}
This work describes a method for the determination of gallic, caffeic and $p$-coumaric acids, as well as quercetin, in Brazilian red wines by employing reverse phase high performance liquid chromatography (RP HPLC) coupled to diode array and mass detectors. The method was performed using a sample volume of $10 \mu \mathrm{L}$. The limits of detections were $0.36,0.27,0.33$ and $0.59 \mathrm{mg} \mathrm{L}^{-1}$ for gallic acid, caffeic acid, $p$-coumaric acid and quercetin, respectively. The precision, as estimated by the relative standard deviation, was between 1.0 and $2.0 \%$ for different concentrations of gallic acid, caffeic acid, $p$-coumaric acid and quercetin. The accuracy was evaluated by addition and recovery experiments, and the obtained values were between approximately 92 and $117 \%$ recovery. The method was then applied to the analysis of red wine samples that were collected from the São Francisco region, Bahia State, Brazil. The concentrations of analytes were determined in ten Brazilian wines and varied from 5.26 to $10.22 \mathrm{mg} \mathrm{L}^{-1}$ for quercetin, 6.65 to $43.92 \mathrm{mg} \mathrm{L}^{-1}$ for gallic acid, 3.58 to $7.83 \mathrm{mg} \mathrm{L}^{-1}$ for $p$-coumaric acid, and 3.59 to $10.5 \mathrm{mg} \mathrm{L}^{-1}$ for caffeic acid.
\end{abstract}

Keywords: chromatographic separation, quercetin, Brazilian red wine, cinnamic acid derivative

\section{Introduction}

It has been reported that phenolic compounds can be of biological benefit to humans by promoting anti-inflammatory, antimicrobial, anticoagulant and antioxidant activities. ${ }^{1}$ It has been suggested that moderate wine intake provides protection against CHD (coronary heart disease) due to the antioxidant properties of its phenolic acids, which delay the onset of atherogenesis and regulate thrombotic tendencies. ${ }^{2}$ The relative contribution of phenolic derivatives to antioxidation is associated with their effectiveness as hydrogen donors, which is dependent on the number and of hydroxyl groups and the extent conjugation, as well as the presence of electron-donating and electron-withdrawing substituents on the aromatic ring. ${ }^{3}$ The occurrence of flavonoids is very common in leaves and fruits, ${ }^{4}$ although it is believed that the antioxidant properties of red wines are linked with total polyphenol concentrations ${ }^{5}$ rather than specific compounds. The polyphenolic derivatives of red grape skin and seeds have some important secondary compounds that are also

*e-mail: fsdias@ufrb.edu.br, jmdavid@ufba.br responsible for antioxidant activity. There are analytical studies about wines analysis that have been reported in the literature. ${ }^{6}$ Many methods have been used to determine the phenolic compounds in wine, but high performance liquid chromatography (HPLC) is the method of choice for this analysis $^{7}$ and is often coupled with UV-Vis, diode array detection (DAD), ${ }^{8}$ electrochemical (ED), ${ }^{9}$ mass spectrometry $(\mathrm{MS})^{10}$ and fluorescence detectors (FD). ${ }^{11}$ The present work describes the determination of gallic acid, caffeic acid, $p$-coumaric acid and quercetin in Brazilian wines produced in the Vale do São Francisco region. This process employs ultrasound extraction and HPLC combined with diode array detectors and mass spectrometry. The method enabled the identification and determination of phenols in different types of wines.

\section{Experimental}

Reagents and solvents

Methanol (J. T. Baker, New Jersey, USA), ethyl acetate, and acetic acid (Merck, Darmstadt, Germany) that were 
used in the process were HPLC grade. Water was supplied by a Millipore (Bedford, MA, USA) Milli-Q water purifier and was used after filtration through a $0.45-\mu \mathrm{m}$ pore size membrane filter. Standards of all the phenolics investigated were obtained from Sigma-Aldrich (St. Louis, MO, USA). The phenolic stock solution (100 $\mathrm{m} \mathrm{L}^{-1}$ ) was prepared in ethanol-water (1:1). The stock solution was diluted to give different standard solutions.

\section{Sample preparation}

Ten samples of different types of red wine were purchased from commercial markets in the city of Salvador (Bahia, Brazil). The samples were chosen for being representative of wines (Shiraz, Cabernet Sauvignon, Shiraz, Tanat, Petite Shirazand the blend Cabernet Sauvignon/Shiraz) produced in the Vale do São Francisco region, Brazil. All wines were stored in the dark at $4{ }^{\circ} \mathrm{C}$ until their analysis.

\section{Extraction procedures}

The following procedure was used to extract phenolic compounds from wine: $20 \mathrm{mg}$ sodium chloride and $20 \mathrm{mg}$ sodium metabisulfite were added to $10 \mathrm{~mL}$ of wine, which was then subjected to three continuous liquid-liquid extractions with $3 \mathrm{~mL}$ of ethyl acetate acidified by $37 \%$ aqueous hydrochloric acid for $10 \mathrm{~min}$ in ultrasound. The extract was evaporated using a rotary evaporator and then dissolved in $1 \mathrm{~mL}$ of an ethanol/water solution $(10: 90 \mathrm{v} / \mathrm{v})$.

\section{Analysis}

The analysis of the samples was performed with an HPLC-DAD-MS model 2010 A in a Shimadzu system (Kyoto, Japan) consisting of an auto sampler LC SIL 10 $\mathrm{AD}$; an ESI (electrospray ionization) interface operating in negative mode with an ion spray voltage of $3000 \mathrm{~V}$ and a capillary temperature of $350{ }^{\circ} \mathrm{C}$, the nebulizing gas flow $\left(\mathrm{N}_{2}\right)$ of $40 \mathrm{~mL} \mathrm{~min}{ }^{-1}$. The instrument was auto tuned for optimum ionization process and sensitivity with polyethylene glycol (PEG) and p-nitro-phenol. Quadrupole mass spectrometer data were collected in full scan mode within a range from 100 to $600 \mathrm{~m} / \mathrm{z}$, with a photodiode array detector (DAD 100). A column C18, 2.1 $\times 75 \mathrm{~mm}$ (particle diameter $3.5 \mu \mathrm{m}$ ) and a guard column (4.6 mm internal diameter $\times 12.5 \mathrm{~mm}$ ) Agilent (California, USA), were employed. The mobile phase was composed of water acidified with formic acid $(\mathrm{pH}=3.0$, solvent $\mathrm{A})$ and methanol (solvent $\mathrm{B}$ ); a flow rate of $0.6 \mathrm{~mL} \mathrm{~min}{ }^{-1}$ was used. The following gradient was used: $0-2 \mathrm{~min}, 15 \% \mathrm{~B} ; 2-7 \mathrm{~min}$,
15-30\% B; 11-15 min, 30-80\% B (cleaning the column); 15-20 min, $80-15 \%$ B (return of the initial conditions). UV absorbance was monitored from 200 to $400 \mathrm{~nm}$.

\section{Results and Discussion}

The phenolic compounds were identified by comparing retention times, UV-Vis spectra and mass spectra obtained from real samples, pure standards (Figures 1 and 2), and real samples spiked with different concentration levels (Table 1). Absorption spectra obtained using a $280 \mathrm{~nm}$ wavelength were utilized to determine the phenolic compounds.

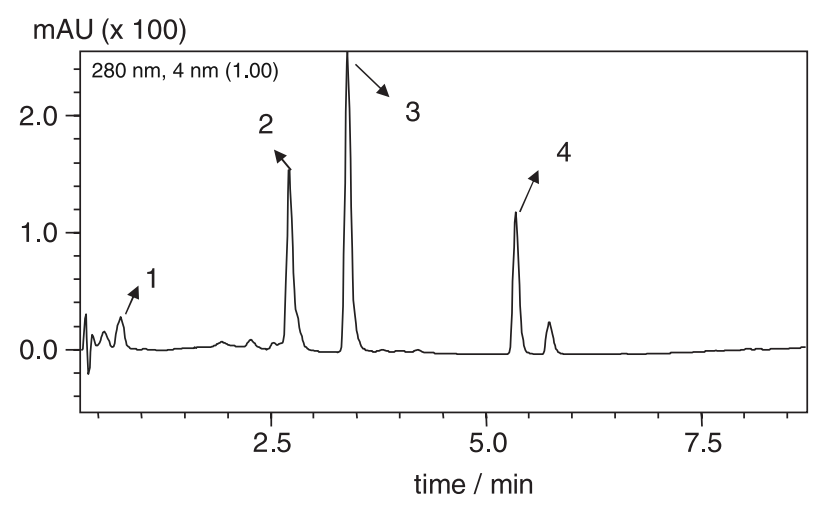

Figure 1. Chromatogram of the standard mixture (peaks 1: gallic acid; 2: caffeic acid; 3: $p$-coumaric acid and 4: quercetin).

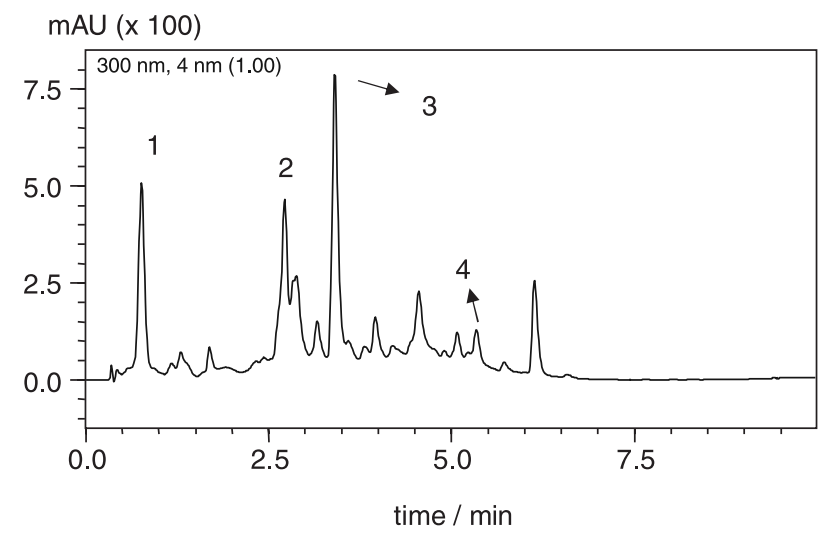

Figure 2. Chromatogram of a representative sample of Brazilian red wine, Cabernet Sauvignon. Peaks 1: gallic acid; 2: caffeic acid; 3: p-coumaric acid; 4: quercetin.

Identification and determination of quercetin, gallic acid, caffeic acid and $p$-coumaric acid in Brazilian wines

Based on the mass spectrum base peak and on the retention times of compounds (Table 2), it was possible to identify and quantify gallic acid, caffeic acid, $p$-coumaric acid and quercetin in wines produced in Vale do São Francisco. By analyzing the MS (Supplementary 
Table 1. Spiked tests for gallic acid, caffeic acid, $p$-coumaric acid, and quercetin in Brazilian wines from Vale do São Francisco. Concentrations (mg L ${ }^{-1}$ ) were obtained by the HPLC-DAD-MS method developed within

\begin{tabular}{|c|c|c|c|c|}
\hline Wine sample & Content / $\left(\mathrm{mg} \mathrm{L}^{-1}\right)$ & Content added / $\left(\mathrm{mg} \mathrm{L}^{-1}\right)$ & Content achieved / $\left(\mathrm{mg} \mathrm{L}^{-1}\right)$ & Recovery $/ \%$ \\
\hline \multicolumn{5}{|l|}{ Petit Shiraz } \\
\hline Gallic acid & 13.8 & 10.0 & 24.0 & 101 \\
\hline Caffeic acid & 4.26 & 5.00 & 9.83 & 113 \\
\hline$p$-Coumaric acid & 4.35 & 5.00 & 9.60 & 106 \\
\hline Quercetin & 5.97 & 6.00 & 11.8 & 97 \\
\hline \multicolumn{5}{|c|}{ Cabernet Sauvignon Shiraz } \\
\hline Gallic acid & 33.3 & 10.0 & 44.0 & 103 \\
\hline Caffeic acid & 10.4 & 6.00 & 16.0 & 96 \\
\hline$p$-Coumaric acid & 7.47 & 6.00 & 14.5 & 114 \\
\hline Quercetin & 9.99 & 10.0 & 20.0 & 100 \\
\hline
\end{tabular}

Information section), it was possible to observe the presence of gallic acid by a negative pseudo-molecular ion $\left([\mathrm{M}-\mathrm{H}]^{-}\right)$ at $m / z 169$ corresponding to gallic acid besides the peak at $\mathrm{m} / \mathrm{z} 338$, which was due to the adduct that formed between two pseudo-molecular ions $\left([\mathrm{M}-\mathrm{H}]^{-}+[\mathrm{M}-\mathrm{H}]^{-}\right)$. Caffeic acid presents an $[\mathrm{M}-\mathrm{H}]^{-}$at $\mathrm{m} / z .179$ (with an adduct peak at $m / z 358)$. $p$-Coumaric acid yields an $[\mathrm{M}-\mathrm{H}]^{-}$at $\mathrm{m} / \mathrm{z} 163$, whereas a peak that is observed at $\mathrm{m} / \mathrm{z} 209$ corresponds to the formation of an adduct between the molecular ion and formic acid from the mobile phase $\left([\mathrm{M}-\mathrm{H}]^{-}+\mathrm{HCOOH}\right)$. The presence of quercetin is indicated by the pseudomolecular ion $[\mathrm{M}-\mathrm{H}]^{-}$at $\mathrm{m} / z, 301$.

Table 2. Selective ion monitoring of a target and retention time for each of the phenolic compounds

\begin{tabular}{lcc}
\hline Analyte & Retention time / min & {$[\mathrm{M}-\mathrm{H}]^{-}(\mathrm{m} / \mathrm{z})$} \\
\hline Gallic acid & 0.75 & 169 \\
Caffeic acid & 2.7 & 179 \\
$p$-Coumaric acid & 3.4 & 163 \\
Quercetin & 5.7 & 301 \\
\hline
\end{tabular}

\section{Analytical features}

The analytical curves were obtained using standard solutions at different concentrations for each analyte. The corresponding regression equations and other characteristic parameters that were used to determine the phenolic compounds are shown in Table 3. The analytical curves exhibit excellent linear behavior over the concentration range that was under study.

The limit of detection (LOD) and the limit of quantification (LOQ) were established by analyzing the calibration curves. ${ }^{12}$ The LOD ranged from 0.27 to $0.59 \mathrm{mg} \mathrm{L}^{-1}$ and the LOQ ranged from 0.90 to $1.96 \mathrm{mg} \mathrm{L}^{-1}$ for all analytes (Table 3).
Relative standard deviations (RSD) calculated for concentrations of 10 and $30 \mathrm{mg} \mathrm{L}^{-1}$ were 1.40 and $1.20 \%$ for gallic acid, 1.63 and $1.08 \%$ for caffeic acid, 1.73 and $1.07 \%$ for $p$-coumaric acid and 1.72 and $1.28 \%$ for quercetin, respectively. In order to evaluate accuracy of the method, addition and recovery tests were performed by comparing the concentrations of the analytes found in four wine samples spiked with known amounts of each polyphenol. The concentrations were then obtained using the corresponding calibration curve, which yielded values that were between approximately 92 and $117 \%$ of the recovery (Table 1).

\section{Application}

Table 4 shows the concentrations of these compounds, as was determined for ten Brazilian wines: quercetin concentrations varied from 5.26 to $10.22 \mathrm{mg} \mathrm{L}^{-1}$, gallic acid varied from 6.65 to $43.92 \mathrm{mg} \mathrm{L}^{-1}, p$-coumaric acid varied from 3.58 to $7.83 \mathrm{mg} \mathrm{L}^{-1}$, and caffeic acid varied from 3.59 to $10.5 \mathrm{mg} \mathrm{L}^{-1}$. Concentration data concerning the concentrations of gallic acid, caffeic acid, $p$-coumaric acid and quercetin found in wines produced in a number of regions have been reported in the literature (Table 5). Minuti and Pellegrino ${ }^{13}$ have found an array of concentrations for different phenolic acids (and quercetin) in red wines, including 33.78 to $104.82 \mathrm{mg} \mathrm{L}^{-1}$ for gallic acid, 0.24 to $4.10 \mathrm{mg} \mathrm{L}^{-1}$ for caffeic acid, 0.30 to $3.39 \mathrm{mg} \mathrm{L}^{-1}$ for p-coumaric acid and 0.03 to $0.98 \mathrm{mg} \mathrm{L}^{-1}$ for quercetin. For wines produced in Hungary, concentration values varied from 29.7 to $79.2 \mathrm{mg} \mathrm{L}^{-1}$ for gallic acid, from 23.3 to $30.8 \mathrm{mg} \mathrm{L}^{-1}$ for caffeic acid, from 0.4 to $8.9 \mathrm{mg} \mathrm{L}^{-1}$ for $p$-coumaric acid, varying from 5.80 to $13.40 \mathrm{mg} \mathrm{L}^{-1}$ for quercetin. ${ }^{14}$

The wide range of phenolic compound concentrations obtained in this work can be explained, at least in part, by the analytical and natural variability of the data. The 
Table 3. Analytical features of the developed HPLC method

\begin{tabular}{lcccc}
\hline Analyte & $\mathrm{LOD}^{\mathrm{a}} /\left(\mathrm{mg} \mathrm{L}^{-1}\right)$ & $\mathrm{LOQ}^{\mathrm{b}} /\left(\mathrm{mg} \mathrm{L}^{-1}\right)$ & Analytical curve & Determination coefficient $\left(\mathrm{R}^{2}\right)$ \\
\hline Gallic acid & 0.36 & 1.19 & Abs $=34330 \mathrm{C}-14743$ & 0.997 \\
Caffeic acid & 0.27 & 0.90 & $\mathrm{Abs}=150669 \mathrm{C}-350791$ & 0.998 \\
$p$-Coumaric acid & 0.33 & 1.10 & Abs $=243971 \mathrm{C}-5435$ & 0.998 \\
Quercetin & 0.59 & 1.96 & Abs $=37745 \mathrm{C}-179854$ & 0.999 \\
\hline
\end{tabular}

a LOD was calculated according to the expression DP $\times 3 / \mathrm{IC}$, where DP is the standard deviation of the response and IC is the slope of the calibration curve; ${ }^{b} \mathrm{LOQ}$ was established by using the expression DP $\times 10 / \mathrm{IC}$.

phenolic composition of red wines is highly complex and closely related to the origin of the grapes, soil type, climate and the wine's production and conservation processes.

The reported data on phenolic compound levels found in Brazilian wines produced in Vale do São Francisco are in accordance with the values that have been found in wine samples from several countries.

\section{Conclusions}

In the present work, we described a simple and sensitive method that allows for the determination of quercetin, gallic acid, caffeic acid and $p$-coumaric acid in the Brazilian red wines of the Vale do São Francisco region. This procedure, which is suitable for routine analyses, includes a stage of ultrasound-assisted liquidliquid extraction that is followed by a chromatographic quantification step. The method is characterized by good precision, linearity and accuracy. The optimized procedure was applied to a wide range of red wines to provide a general knowledge regarding the content of common antioxidants in wines.

\section{Supplementary Information}

Supplementary data (ESI mass spectra of the phenolics) are available free of charge at http://jbcs.sbq.org.br as PDF file.

Table 4. Concentrations of gallic, caffeic and $p$-coumaric acids and quercetin found in Brazilian wines

\begin{tabular}{lcccc}
\hline Wine sample & Gallic acid / $\left(\mathrm{mg} \mathrm{L}^{-1}\right)$ & Caffeic acid / $\left(\mathrm{mg} \mathrm{L}^{-1}\right)$ & $p$-Coumaric acid / $\left(\mathrm{mg} \mathrm{L}^{-1}\right)$ & Quercetin / $\left(\mathrm{mg} \mathrm{L}^{-1}\right)$ \\
\hline Petit Shiraz & $13.76 \pm 0.19$ & $4.26 \pm 0.04$ & $4.35 \pm 0.31$ & $5.97 \pm 0.08$ \\
Cabernet Sauvignon & $12.94 \pm 0.56$ & $4.94 \pm 0.08$ & $4.33 \pm 0.09$ & $6.27 \pm 0.07$ \\
Ruby Cabernet & $11.29 \pm 0.36$ & $4.69 \pm 0.13$ & $5.06 \pm 0.13$ & $6.39 \pm 0.09$ \\
Tannat & $9.03 \pm 0.35$ & $3.59 \pm 0.09$ & $3.58 \pm 0.08$ & $6.95 \pm 0.61$ \\
Cabernet Sauvignon & $6.65 \pm 0.36$ & $4.13 \pm 0.46$ & $2.88 \pm 0.17$ & $5.26 \pm 0.18$ \\
Shiraz & $11.29 \pm 0.71$ & $5.10 \pm 0.22$ & $4.40 \pm 0.16$ & $6.02 \pm 0.12$ \\
Cabernet Sauvignon Shiraz & $43.92 \pm 0.51$ & $10.00 \pm 0.21$ & $6.87 \pm 0.18$ & $9.56 \pm 0.76$ \\
Cabernet Sauvignon & $38.31 \pm 0.41$ & $8.79 \pm 0.11$ & $5.63 \pm 0.81$ & $9.13 \pm 0.75$ \\
Cabernet Sauvignon & $30.98 \pm 0.84$ & $8.52 \pm 0.59$ & $7.83 \pm 0.12$ & $10.22 \pm 0.81$ \\
Cabernet Sauvignon Shiraz & $33.33 \pm 1.05$ & $10.45 \pm 0.54$ & $7.47 \pm 0.15$ & $9.99 \pm 0.32$ \\
\hline
\end{tabular}

Table 5. Review about the concentration of gallic acid, caffeic acid, $p$-coumaric acid and quercetin concentrations in wine from different regions

\begin{tabular}{lccccc}
\hline Country & Gallic acid & Caffeic acid & $p$-Coumaric acid & Quercetin & Reference \\
\hline Italy & $33.8-104.8$ & $0.24-4.10$ & $0.30-3.39$ & $0.03-0.98$ & 13 \\
Hungary & $29.7-79.2$ & $23.3-30.8$ & $0.4-8.9$ & $5.80-13.4$ & 14 \\
Czech Republic & 1.4 & $0.46-0.8$ & $0.18-0.8$ & $\mathrm{ND}^{\mathrm{a}}$ & 15 \\
Spain & - & $6.6-21.26$ & $11.67-14.19$ & $7.4-9.75$ & 16 \\
Brazil & $6.7-44.0$ & $3.6-10.5$ & $2.88-7.9$ & $5.3-10.3$ & this work \\
\hline
\end{tabular}

aND: not detected. 


\section{Acknowledgments}

The authors are grateful to PRONEX/FAPESB, Conselho Nacional de Desenvolvimento Científico e Tecnológico (CNPq) and CAPES for providing grants and fellowships.

\section{References}

1. Barreiros, A. L. B. S.; David, J. M.; David, J. P.; Quim. Nova 2006, 29, 113.

2. Frankel, E. N.; Kanner, J.; German, J. B.; Parks, E.; Kinsella, J. E.; Lancet 1993, 341, 454; Pandey, K. B.; Rizvi, S. I.; J. Braz. Chem. Soc. 2010, 21, 909.

3. Rice-Evans, C. A.; Miller, N. J.; Bolwell, P. G.; Bramley, P. M.; Escarpa, A.; Gonzalez, M. C.; J. Chromatogr. A 2000, 897, 161; Miller, N. J.; Rice Evans, C. A.; Davies, M. J.; Clin. Sci. 1993, $84,407$.

4. Barreiros, A. L. B. S.; David, J. M.; David, J. P.; de Queiroz, L. P.; Phytochemistry 2000, 55, 805; Felício, J. D.; Rossi, M. H.; Park, H. R.; Gonçalvez, E.; Braggio, M. M.; David, J. M.; Cordeiro, I.; Fitoterapia 2001, 72, 453.

5. Esparza, I.; Santamaría, C.; Calvo, M. I.; Fernández, J. M.; Microchem. J. 2009, 9132.

6. Bentlin, F. R. S.; Pulgati, F. H.; Dressler, V. L.; Pozebon, D.; J. Braz. Chem. Soc. 2011, 22, 327; Welke, J. E.; Hoeltz, M.; Dottori, H. A.; Noll, I. B.; J. Braz. Chem. Soc. 2010, 21, 441; Dias, F. S.; Silva, M. F.; David, J. M.; Food Anal. Methods 2013,
6, 963; Welke, J. E.; Zanus, M.; Lazarotto, M.; Schmitt, K. G.; Zini, C. A.; J. Braz. Chem. Soc. 2012, 23, 678.

7. Pereira, V.; Câmara, J. S.; Cacho, J.; Marques, J. C.; J. Sep. Sci. 2010, 33, 1204; Mercolini, L.; Saracino, M. A.; Bugamelli, F.; Ferranti, A.; Malaguti, M.; Hrelia, S.; Raggi, M. A.; J. Sep. Sci. 2008, 31, 1007.

8. Aznar, Ò.; Checa, A.; Oliver, R.; Hernández-Cassou, S.; Saurina, J.; J. Sep. Sci. 2011, 34, 527.

9. Kolouchová-Honzlíková, I.; Melzoch, K.; Filip, V.; Smidrkal, J.; Food Chem. 2004, 87, 151.

10. Flamini, R.; Mass Spectrom. Rev. 2003, 22, 218; Spácil, N. Z. L.; Solich, P.; Talanta 2008, 76, 189.

11. Vitrac, X.; Monti, J. P.; Vercauteren, J.; Deffieux, G.; Mérillon, J. M.; Anal. Chim. Acta 2002, 458, 103; Dias, F. S.; Lovillo, M. P.; Barroso, C. G.; David, J. M.; Microchem. J. 2010, 96, 17.

12. Numanoğlu, E.; Boyaci, İ. H.; Topcu, A.; J. Food Drug Anal. 2008, 16, 74.

13. Minuti, L.; Pellegrino, R.; J. Chromatogr. A 2008, 1185, 23.

14. Nikfardjam, M. S. P.; Márk, L.; Avar, P.; Figler, M.; Ohmacht, R.; Food Chem. 2006, 98, 453.

15. Sladkovský, R.; Solich. P.; Urbánek, M.; J. Chromatogr. A 2004, 1040, 179.

16. Rodríguez-Delgado, M. A.; Pérez, M. L.; Corbella, R.; González, G.; García Montelongo, F. J.; J. Chromatogr. A 2000, $87,427$.

Submitted: August 25, 2015 Published online: December 22, 2015 